\title{
Harvest of table olives by mechanical harvesting equipment
}

\author{
Filippo Gambella \\ Università degli Studi di Sassari, Dipartimento Agraria, Sassari, Italy
}

\begin{abstract}
In this work, we have evaluated the performance, of an electric comb equipped with five undulated fingers used for mechanized the harvesting of table olives. The first aim of the work was to test three different types of coating materials used for covering the fingers: Silicon (S), Vulcanized rubber (VR) and Natural rubber (NR). The diameter of the coating materials tested were $7 \mathrm{~mm}$ (D1), $14 \mathrm{~mm}$ (D2), $19 \mathrm{~mm}$ (D3) in order to evaluate the damage of different working conditions on the intact olives. During harvesting, silicon at $7 \mathrm{~mm}$ and $14 \mathrm{~mm}$ resulted in the largest percentage of undamaged the fruit ( $67 \%$ and $65 \%)$, natural rubber $63 \%$ and vulcanized rubber at the $54 \%$. The second aim was to evaluate the combination, in terms of the best performance, of the machines used for mechanized harvesting of table olives. Several factors have been examined: undulating fingers variation thickness, different rotational speeds and different coating materials used to reduce the impact damage on olives. From the tests on olive tree we have determined that while plastic materials (S) and (NR) appear to have a positive role in harvest quality, the vibration transmitted to the operator's hand is great from $6.48 \mathrm{~m} / \mathrm{s} 2$ for $\mathrm{S}$ to $6.31 \mathrm{~m} / \mathrm{s} 2$ for NR and 2.92 $\mathrm{m} / \mathrm{s} 2$ for VR, respect to the materials used.
\end{abstract}

\section{Introduction}

Hand harvesting of table olives is expensive because it involves a large number of workers and thus high labor costs, but it does ensure a high quality of the final product. To reduce production costs, many olive operation are now using mechanical harvesting equipment (Ferguson, 2006). The use of hand-held machines in olive harvesting have always been marked by a lack of information from an ergonomic point of view. The hand-held harvesting can expose the workers to

Correspondence: Filippo Gambella. Sezione di Ingegneria del Territorio. Dipartimento di Agraria, Università degli Studi di Sassari, Viale Italia 39, 07100 Sassari, Italy.

Tel. +39079229281 - Fax +3909229285 .

E-mail: gambella@uniss

Key words: electric comb; tables olives; harvesting tools.

(C) Copyright F. Gambella 2013

Licensee PAGEPress, Italy

Journal of Agricultural Engineering 2013; XLIV(s2):e78

doi:10.4081/jae.2013.s2.e78

This article is distributed under the terms of the Creative Commons Attribution Noncommercial License (by-nc 3.0) which permits any noncommercial use, distribution, and reproduction in any medium, provided the original author(s) and source are credited. noise, vibrations transmitted to the hand-arm system (Cerruto et al., 2009; Deboli et al., 2008; Gambella et al. 2012; Pretti et al. 2013) and arm muscle fatigue due to the machine weight. Essentially, tables olive harvesters can use three different systems to detach the fruit: 1) shaking the trunk, applied in traditional or intensive groves; 2) directly shaking specific areas of canopy using hand portable vibrating combs with rotating heads, suitable even for large trees and expanded canopies; 3 ) laterally shaking the canopy of the entire plant using a straddle engine with bilateral sets of shaking rods, borrowed from viticulture, on hedge trained plants. Trunk shakers, electrical comb, rake stripper and others typologies of harvesters are widely used in the mechanical harvesting of oil olive groves (Gil-Ribes et al., 2009, Paschino et al. 2010). However, the table olives had a number of various factors that make the use of the shakers difficult and among that limits its use are: high fruit retention force, high fruit bruise susceptibility, lack of tree pruning adaption to mechanical harvesting and the hand-arm vibration transmitted to operators. All of these limitations imply in some cases a low harvesting efficiency and high percentage of damaged fruit (Kouraba et al., 2004; Ferguson et al., 2010; ) A preliminary study on the fruit damage was carried out by Paschino et al. (2010) on the use of electric hand-held harvesters, equipped with titanium undulating fingers coated with silicon, and on the damage produced by the different working conditions during harvesting of table olives. Experiments in the field have highlighted that during table olive harvesting contact between undulating teeth with reduced coating thickness and the fruit increased the damage by nearly $60 \%$ (Paschino et al. 2010). Another study investigated the level of vibration generated by three different types of plastic coating materials used on titanium fingers in order to minimize the damage to the olives. The mechanical damage during harvesting consists of local tissue degradation combined with an output of intracellular water and the oxidation of phenolic compounds after impact (Segovia-Bravo et al., 2009). The oxidation process produces a darkening of the green color on the olive surface. After some time, depending on the intensity and characteristics of the impact, the area effected begins to darken, first superficially, then spreading deeper into the flesh until it reaches the endocarp (Ben-Shalom et al., 1978) of the olive.

\section{Aim of the work}

The purpose of this study was to evaluate the performance of an hand-held olive harvester consisting of an electric comb equipped with fingers coated with various materials and to assess olive the damage during harvesting. Additionally we measured the level of vibration transmitted to the operator's hand by the harvesting equipment.

\section{Materials and methods}

The harvesting trials were carried out on a farm which specialized in table olives production, located in the plain of Ozieri, northern 
Sardinia, Italy. The "Manna" (Olea Europea L.) cultivar was used in this experiment. the harvesting test was conducted in the first 10 days of January 2012 during the green maturation stage. The olives were harvested from 54 plants and graded by size with divergent wires. The electric comb used was mounted on a telescopic pole and powered by an electrical DC power pack (ISO-Tech). In order to reduce the probability of impact damage, three different coatings for undulating fingers were prepared with overall diameter of $7.1 \mathrm{~mm}$ (D1), $13.9 \mathrm{~mm}$ (D2) and 19.2 mm (D3). Three different types of elastic material, Silicon (S), Vulcanized rubber (VR) and Natural rubber (NR), with three different hardness value in Sh.A scale were also used for each diameter: Silicon (Sh.A 50); Natural Rubber Sh.A (45-55) Vulcanized Rubber Sh.A (8090) (Fig. 1). An acquisition system (Larson Davis, model HVM1009) for measuring vibrations was used to measure and recording hand-arm vibration exposure. A triaxial accelerometer, which measures the vibrations along the three axes ( $\mathrm{x}, \mathrm{y}$ and $\mathrm{z}$ ) simultaneously, was used. The accelerometer model was SEN020 PCB (ICP Company) positioned on the top of the hand grip, to assess the tool vibration.

\section{Damage evaluation of fruit}

The harvested olives were classified according to the different kinds of damage that was found on the skin and based on previous experiments carried out with the same harvester. For each classified group of olives, all were exposed to air for 24 hours to allow for oxidation. This allowed on damage caused by harvesting equipment to become visually evident. The impact damage caused by undulating fingers contact was visually assessed using the system proposed by Mohsenin, (1996) and Treeamnuk et al. (2010) as shown in Figure 2. The biological damage was classified using the system proposed by Riquelme et al. (2007). Three types of damage were identified for all the harvested olives and these were divided up as follows:

- $\quad 1^{\text {st }}$ class-damaged olives during the harvesting phase (Fig. 2a and 2b).

$2^{\text {rd }}$ class-biologically damaged olives.

$3^{\text {th }}$ class-intact or undamaged olives after harvesting.

The following formulae were used to classify the harvested olives, based on the detected damage:

Damage \% per class of olives $1^{\text {st }}, 2^{\text {nd }}$ and $3^{\text {th }}=\left(n^{\circ}\right.$ of damaged olives $/ n^{\circ}$ of olives harvested from the plant $)^{*} 100$

In each individual case, the percentage of intact olives was obtained from the difference between the overall total, the percentage of damaged olives and the percentage of olives with biological damage.

\section{Statistical analysis results}

The General Linear Model (GLM) procedure of Minitab 16 Ltd software was used to statistically analyze the data on the percentage of intact fruit and the damaged percentage of olives harvested with three different thicknesses of undulating fingers, the three different speeds and with three different types of plastic materials. The following formula was used, $\mathrm{y}=\mathrm{D}+\mathrm{V}+\mathrm{M}+\mathrm{D}^{*} \mathrm{~V}+\mathrm{D}^{*} \mathrm{M}+\mathrm{M} * \mathrm{~V}$, where $\mathrm{y}$, each time, is the percentage of intact olives and the percentage of olives damaged by impact; D, each time, is the overall diameter of the coating of undulating fingers (3 levels: D1, D2 and D3); $\mathrm{V}$ each time, is the rotational speed of undulating fingers ( 3 levels: V1; V2 and V3); M is the type of plastic material used for coating the undulating fingers (3 levels: M1, $\mathrm{M} 2$ and $\mathrm{M} 3$ ). $\mathrm{D}^{*} \mathrm{~V}, \mathrm{D}^{*} \mathrm{M}$ and $\mathrm{M}^{*} \mathrm{~V}$ are the interactions between the above listed factors. The multiple comparisons were computed using Tukey's test (confidence $=95 \%$ ). The data of the level of vibration transmitted to the operator's hand were statistically analyzed by simple analysis of variance (ANOVA). The means were separated with the Kruskal-Wallis test. The level of statistical significant was stabled at $p$ $\leq 0.005$

\section{Results}

Table 1 outlines the percentages of intact olives. The variance analysis for damage showed significant results only for materials. The thickness of the coating also had a significant impact on the percentage of damage. Specifically, $35 \%$ of olives harvested with a thickness of D1 showed significant more damage than those harvested with thicknesses of D2 and D3. Average damage (5.34\%) was markedly less when vulcanized rubber was used than when silicon (19.48\%) or natural rubber (19.89\%) was used (Table 1). In terms of the efficiency of the material used, if one adds the percentage of impact damage to those of intact

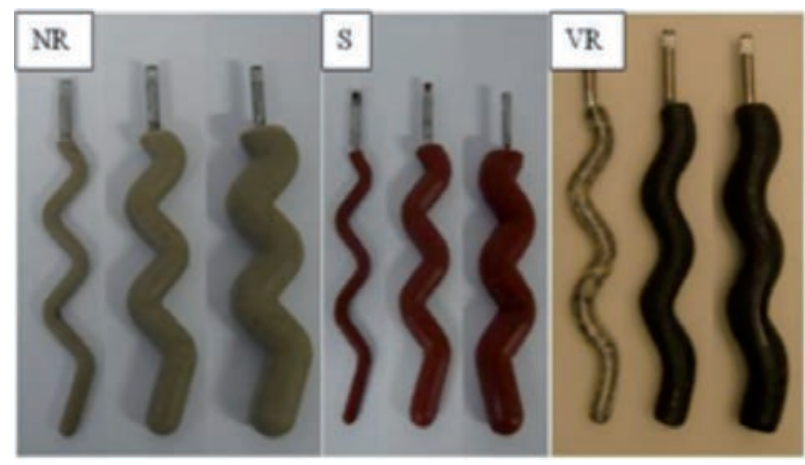

Figure 1. The different types of plastic material applied to the rotating fingers: (NR) natural rubber, $(S)$ silicon and (VR) vulcanized rubber.

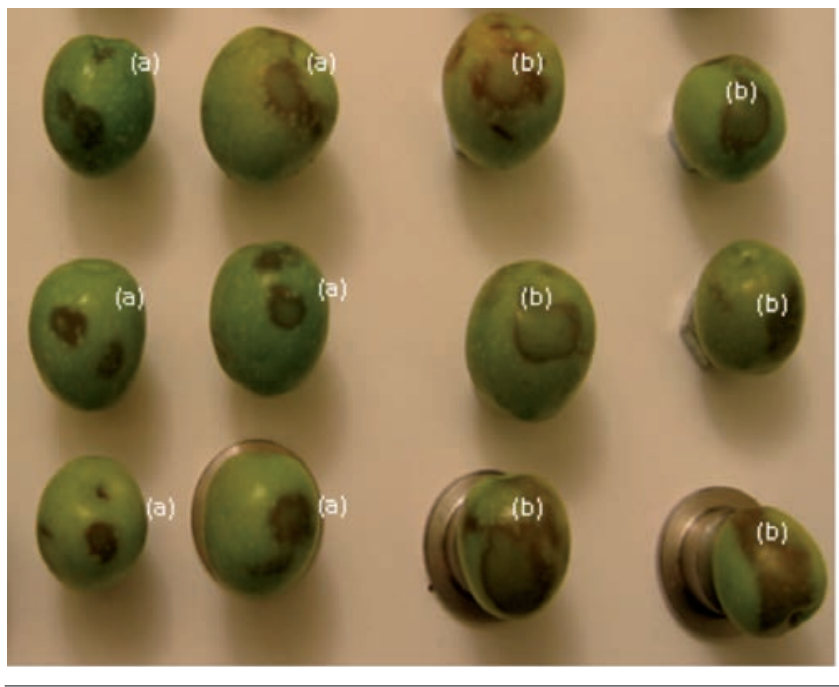

Figure 2. Classification of damages detected during mechanized harvesting and 24 hours ofter the exposure of drupes to air: (a) example of superficial impact damage caused by undulating teeth consequently the combing operation; (b) deep damage caused by the insertion of the drupe between the undulating teeth and the rotation block of the mechanical harvesting tools. 
olives, then the percentages of potentially transformable fruit are $85.9 \%, 95.1 \%$ and $97.7 \%$ for VR, NR and S, respectively. Direct observation of the olives also showed that olives harvested with undulating fingers coated with silicon were more intact than those harvested with undulating fingers coated with vulcanized rubber (Table 1). There were significant differences in the percentages of intact olives, depending on the thickness of the coatings. The results were $36.75 \%$ intact with D1, 56.00\% intact with D2 and 61.89\% intact with D3. These results highlight that the best results are obtained with coatings D2 and D3 (Table 1). The rotational speed also had a significant effect on the results. As the rotation of the fingers increased the percentage of intact olives decreased (62.31\% with V1, $56.07 \%$ with V2 and $36.16 \%$ with V3), irrespective of the thickness of the coating (Table 1). The material used did not significantly affect on the percentage of intact olives. This type varied from $47 \%$ for natural rubber to $56 \%$ for silicon (S).

There were significant differences in results depending on the coating material used when the smallest thickness was used (D1), but this was not true for D2 and D3. Table 2 illustrates the percentages of intact olives. There were a significant percentage of olives harvested suitable for transformation in brine, when the silicone or natural rubber was used for coatings the finger, while for the fingers coated with vulcanized rubber the percentage of intact olives were $54.1 \%$ and $54.4 \%$.

When the D1 and D2 thickness in natural rubber or in silicon was used, the percentage of intact olives decrease from $63.8 \%$ to $60.8 \%$ to the first and from $67.5 \%$ to $65.0 \%$ to the second. Vulcanized rubber with D1 and D2 thickness, had the same percentage of intact olives 54.1\% and $54.4 \%$. The percentage of intact fruit rose from $17.6 \%$ to the natural rubber, to the $42.2 \%$ of the vulcanized rubber respectively (Table 2 ). In terms of operative parameters, the best combination appear when was used the natural rubber or the silicon at the D1 or D2 thickness. All the plastic materials utilized show a low quality of the olives harvested when were used with the thickness D3 (Table 2).

Table 3 shows the values of acceleration weighted with the machines used on olive trees at the rotation speed of $4000 \mathrm{rev} / \mathrm{min}$, set by the producer, but considering all the sizes of finger coated (D1, D2 and D3) and types of material used (natural rubber, silicon, and vulcanized rubber). Data were also analyzed to assess rotational speed of the combing fingers. The fingers coated with silicon and vulcanized rubber produced dynamic acceleration levels increasing in function of the thickness. Different outcome had the rake type NR. In fact, it, with a thickness D2, the acceleration value was $5.73 \mathrm{~m} / \mathrm{s}^{2}$, lower than the thickness D1 and D3 $\left(6.31 \mathrm{~m} / \mathrm{s}^{2}\right.$ and $9.59 \mathrm{~m} / \mathrm{s}^{2}$ respectively.

The value of maximum acceleration equal to $11.38 \mathrm{~m} / \mathrm{s}^{2}$ was produced by silicon comb with a thickness D3, while the vulcanized rubber comb had values of $7.19 \mathrm{~m} / \mathrm{s}^{2}$. Also during the dynamic combing, the fingers mounted in the harvesting head produced an abnormal kinematic behavior, due to the excessive thickness of the material used for the fingers coating. For the D2 thickness the vulcanized rubber had a value of acceleration equal to $3.92 \mathrm{~m} / \mathrm{s}^{2}$ (almost three times less than the fingers coated with silicon, $11.37 \mathrm{~m} / \mathrm{s}^{2}$ ), while the natural rubber reported $5.73 \mathrm{~m} / \mathrm{s}^{2}$. For the thickness D1 and D3, the lower acceleration values are $2.92 \mathrm{~m} / \mathrm{s}^{2}$ and $7.19 \mathrm{~m} / \mathrm{s}^{2}$ for fingers coated with the material vulcanized rubber. For the thickness D1, the highest acceleration value is 6.48 $\mathrm{m} / \mathrm{s}^{2}$, produced by the silicon type. For the natural rubber type, the maximum acceleration was $9.59 \mathrm{~m} / \mathrm{s}^{2}$ for the thickness D3, while for the thickness D1 was $6.31 \mathrm{~m} / \mathrm{s}^{2}$ at the same rotation speed. The statistical analysis with rotation speeds of $4000 \mathrm{rev} / \mathrm{min}$ shows a significant difference in working conditions considered. The significant statistical differences assigned to all the three materials three different behaviors, even if the minimum values of acceleration were recorded for all

Table 1. Variance analysis of foliage and branches damage, impact damage and intact fruits.

\begin{tabular}{lccc} 
Thickness & Foliage and branches & Impact & Intact fruits \\
$7 \mathrm{~mm}(\mathrm{D} 1)$ & $14.62( \pm 3,36)$ & $34.49^{\mathrm{a}}( \pm 3,10)$ & $36.75^{\mathrm{a}}( \pm 5,41)$ \\
$14 \mathrm{~mm}$ (D2) & $16.58( \pm 3,36)$ & $24.94^{\mathrm{b}}( \pm 3,10)$ & $56.00^{\mathrm{b}}( \pm 5,41)$ \\
\hline $19 \mathrm{~mm}$ (D3) & $13.51( \pm 3,36)$ & $20.13^{\mathrm{b}}( \pm 3,10)$ & $61.80^{\mathrm{b}}( \pm 5,41)$ \\
Speed (rpm) & & & \\
V1 & $11.68( \pm 3,36)$ & $23.36( \pm 3,10)$ & $62.31^{\mathrm{b}}( \pm 5,41)$ \\
V2 & $14.08( \pm 3,36)$ & $21.64( \pm 3,10)$ & $56.07^{\mathrm{b}}( \pm 5,41)$ \\
\hline V3 & $18.96( \pm 3,36)$ & $34.56( \pm 3,10)$ & $36.16^{\mathrm{a}}( \pm 5,41)$ \\
Materials (Type) & & $27.83( \pm 3,10)$ & $47.38( \pm 5,41)$ \\
Natural rubber (NR) & $19.89 \mathrm{a}( \pm 3,36)$ & $30.39( \pm 3,10)$ & $50.26( \pm 5,41)$ \\
Vulcanized rubber (VR) & $5.34 \mathrm{~b}( \pm 3,36)$ & $21.39( \pm 3,10)$ & $56.91( \pm 5,41)$ \\
\hline Silicon (S) & $19.48 \mathrm{a}( \pm 3,36)$ & \\
\hline
\end{tabular}

Means that do not share "a" letter are significantly different ( $\mathrm{p} \leq 0.005)$. Grouping information using tukey method and 95,0\% confidence.

Table 2 The percentage values of intact fruits harvested with undulating teeth coated with different plastic materials: natural rubber (NR), Silicon (S) and Vulcanized rubber (VR).

\begin{tabular}{lccc} 
Thickness & $\begin{array}{c}\text { Percentage of intact olives } \\
\text { (Natural rubber) }\end{array}$ & $\begin{array}{c}\text { Percentage of intact olives } \\
\text { (Silicon) }\end{array}$ & $\begin{array}{c}\text { Percentage of intact olives } \\
\text { (Vulcanized rubber) }\end{array}$ \\
$7 \mathrm{~mm}$ (D1) & $63.8^{\mathrm{a}}$ & $67.5^{\mathrm{a}}$ & $54.1^{\mathrm{ab}}$ \\
$14 \mathrm{~mm}$ (D2) & $60.8^{\mathrm{ab}}$ & $65.0^{\mathrm{a}}$ & $54.4^{\mathrm{ab}}$ \\
\hline $19 \mathrm{~mm}$ (D3) & $17.6^{\mathrm{b}}$ & $38.2^{\mathrm{ab}}$ & $42.2^{\mathrm{ab}}$ \\
\hline
\end{tabular}

Means that do not share "a" letter are significantly different ( $\mathrm{p} \leq 0.005)$. 
Table 3. RMS acceleration measured on the olive tree tests with the three different types of plastic materials: silicone, vulcanized rubber and natural rubber.

\begin{tabular}{|c|c|c|c|c|}
\hline $\begin{array}{l}\text { Teeth Material } \\
\text { S = Silicone } \\
\text { NR = Natural rubber } \\
\text { VR = Vulcanized rubber }\end{array}$ & $\begin{array}{c}\text { Thickness } \\
\text { mm }\end{array}$ & $\begin{array}{c}\text { Operative condition } \\
\text { Revolution per minutes } \\
\text { rpm }\end{array}$ & $\begin{array}{l}\text { Olive tree } \\
\text { working condition }\end{array}$ & $\begin{array}{l}\text { Global acceleration (RMS) } \\
\qquad\left(\mathrm{m} / \mathrm{s}^{2}\right)\end{array}$ \\
\hline S & 7 (D1) & 4000 (V3) & combing & $6,48^{\mathrm{a}}$ \\
\hline NR & 7 (D1) & 4000 (V3) & combing & $6,31^{\mathrm{a}}$ \\
\hline VR & 7 (D1) & 4000 (V3) & combing & $2,92^{b}$ \\
\hline S & 14 (D2) & 4000 (V3) & combing & $11,37^{\mathrm{a}}$ \\
\hline NR & 14 (D2) & 4000 (V3) & combing & $5,73^{b}$ \\
\hline VR & 14 (D2) & 4000 (V3) & combing & $3,92^{\mathrm{c}}$ \\
\hline S & 19 (D3) & 4000 (V3) & combing & $11,38^{\mathrm{a}}$ \\
\hline NR & 19 (D3) & 4000 (V3) & combing & $9,59^{\mathrm{b}}$ \\
\hline VR & 19 (D3) & 4000 (V3) & combing & $7,19^{c}$ \\
\hline
\end{tabular}

Averages where do not appear the letter a are statistically different for $\mathrm{p} \leq 0,05$

the tests conducted with the protective material with greater rigidity as that of vulcanized rubber type (Table 3). From tree tests, it can be deduced that in tests on olive tree materials silicon and natural rubber appear to have a positive role in increasing vibration (from $6.48 \mathrm{~m} / \mathrm{s}^{2}$ for silicon to $6.31 \mathrm{~m} / \mathrm{s}^{2}$ for natural rubber and $2.92 \mathrm{~m} / \mathrm{s}^{2}$ for vulcanized rubber), with respect to the material used.

\section{Conclusions}

This research demonstrated that the type and thickness of materials used on the harvesting fingers are important consideration when harvesting table olives.

The tests using natural rubber or silicon with D1 and D2 thicknesses resulted in between $65 \%$ and $67 \%$ of intact fruit. These results are significantly higher than those for fruit harvested with undulating fingers coated with vulcanized rubber for all three types of undulating fingers considered. The working conditions used allowed for variations in the rotational speeds. When the percentage of intact drupes is added to those potentially transformable (foliar and branches damage and contact damage), the percentage of transformable fruit ranges from $85.6 \%$ with D1 to $97.5 \%$ with D2 and $95.4 \%$ with D3. In terms of the material used the trend is similar, with the percentage of transformable drupes rising from $85.9 \%$ when vulcanized rubber is used to $95.1 \%$ with natural rubber and $97.7 \%$ with silicon.

The hand-arm vibration from the different comb models tested depended mainly from kinematics of the comb used, varying in the different trials from a minimum of $2.92 \mathrm{~m} / \mathrm{s}^{2}$ to a maximum of 11.38 .4 $\mathrm{m} / \mathrm{s}^{2}$. Probably this aspect is the main element to be taken into account by the ergonomic point of view. With the same diameters (D2 and D3), silicon, natural rubber and vulcanized rubber, in all tests, produced higher levels of acceleration (i.e. $11.38 \mathrm{~m} / \mathrm{s}^{2} 11.37 \mathrm{~m} / \mathrm{s}^{2}$ ) in silicon D2 and D3. Finally, even for the thickness of $7 \mathrm{~mm}$ was found the same results with the silicon and natural rubber with acceleration levels higher than the vulcanized rubber $\left(6.48 \mathrm{~m} / \mathrm{s}^{2}\right.$ silicon, $6.31 \mathrm{~m} / \mathrm{s}^{2}$ natural rubber and $2.92 \mathrm{~m} / \mathrm{s}^{2}$ vulcanized rubber).

The statistical analysis showed similar behavior for the two materials of the elastic type, different from the more rigid material (vulcan- ized rubber). The action of the foliage certainly affects the level of acceleration transmitted to the hands of workers, because of olive trees have been recorded different global acceleration values. Finally, taking into account the measurements made during collection, can derive specific guidelines on the use of personal protective equipment.

This results in the later formation of more or less extensive superficial browning, and injuries of different depths. The value of the product is reduced and there is a loss of product consistency. The information obtained on table olive damage during fruit detachment with an electric comb can be used by the producers to determine how to reduce and prevent bruising during harvesting operations.

\section{References}

Ferguson L. Trends in olive fruit handling previous to its industrial transformation. Grasas y Aceites 2006, 57 1:9-15.

Cerruto E., Manetto G., Schillaci G. 2009. Electric Shakers to Facilitate Drupes Harvesting: Measurement of the Vibrations Transmitted to the Hand-Arm System. XXXIII CIOSTA-CIGR V Conference on "Technology and management to ensure sustainable agriculture, agro-systems, forestry and safety", Reggio Calabria, June 17-19, 2009.

Deboli R., Calvo A., Preti C. The Use of a Capacitive Sensor Matrix to Determine the Grip Forces Applied to the Olive Hand Held Harvesters, Proceedings of the International Conference on "Innovation Technology to Empower Safety, Health and Welfare in Agriculture and Agro-food Systems", Ragusa, September 15-17, 2008.

Gambella F., Deboli R., Preti C., Calvo A. Vibration transmitted to operator's hands by a new type of rotary pick-up for the harvest of table olives. International Conference RAGUSA SHWA 2012, September 3-6, 2012, Ragusa - Italy "Safety Health and Welfare in Agriculture and in Agro-food Systems", 381-387.

Preti C., Gambella F., Deboli R., Calvo A., Inserillo M., Dau R. and Casu E. C. Vibration level generated by a rotary pick-up for the harvest of table olives. AIA - DAGA 2013 Conference on Acoustics March 1821 2013. Merano. 
Gil-Ribes JA, Blanco-Roldán GL, Castro-García S, 2009. Mecanización del cultivo y de la recolección en el olivar. Junta de Andalucía, Sevilla, Spain. 195 pp.

Paschino F, Caria M, Gambella F. The Harvest of Table Olives from the Plant by Means of an Hand Harvester" International Conference Ragusa SHWA-September 16-18, 2010 Ragusa Ibla Campus- Italy "Work Safety and Risk Prevention in Agro-food and Forest Systems" 2010, 656-663.

Kouraba K, Gil-Ribes JA, Blanco-Roldán GL, De Jaime- Revuelta MA, Barranco D,. Suitability of olive varieties for mechanical harvester shaking; Olivae; 2004 101: 39-43.

Ferguson L., Rosa UA, Castro-Garcia S., Lee SM, Guinard JX, Burns J, Krueger WH, O'Connell NV, Glozer K. Mechanical harvesting of California table and oil olives. Adv. Hort. Sci., 201024 (1): 53-63
Segovia-Bravo KA, Jaren-Galan M, García-García P, Garrido-Fernández A, 2009. Browning reactions in olives: mechanism and polyphenols involved. Food Chem 114: 1380-1385.

Ben-Shalom N, Harel E, Mayer AM, 1978. Enzymic browning in green olives and its prevention. J Sci Food Agric 29: 398-402.

Mohsenin N.N. Physical properties of plant and animal materials. New York: Gordon and Breach Science Publishers; 1996. Chapter 8 page 383-493.

Treeamnuk K, Pathaveerat S, Terdwongworakul A, Bupata C. Design of machine to size java apple fruit with minimal damage. Biosystem Engineering 2010 7:140-148.

Riquelme MT, Barreiro P, Ruiz-Altisent M, Valero C. Olive classification according to external damage using image analysis. Journal of Food Engineering 2008, 87 371-379. 